\title{
Diversity of the Bosmina (Cladocera: Bosminidae) in China, revealed by analysis of two genetic markers (mtDNA 165 and a nuclear ITS)
}

\author{
Liufu Wang, Hang Zhuang, Yingying Zhang and Wenzhi Wei
}

\begin{abstract}
Background: China is an important biogeographical zone in which the genetic legacies of the Tertiary and Quaternary periods are abundant, and the contemporary geography environment plays an important role in species distribution. Therefore, many biogeographical studies have focused on the organisms of the region, especially zooplankton, which is essential in the formation of biogeographical principles. Moreover, the generality of endemism also reinforces the need for detailed regional studies of zooplankton. Bosmina, a group of cosmopolitan zooplankton, is difficult to identify by morphology, and no genetic data are available to date to assess this species complex in China. In this study, 48 waterbodies were sampled covering a large geographical and ecological range in China, the goal of this research is to explore the species distribution of Bosmina across China and to reveal the genetic information of this species complex, based on two genetic markers (a mtDNA 165 and a nuclear ITS). The diversity of taxa in the Bosmina across China was investigated using molecular tools for the first time.

Results: Two main species were detected in 35 waterbodies: an endemic east Asia B. fatalis, and the B. longirostris that has a Holarctic distribution. B. fatalis had lower genetic polymorphism and population differentiation than B. Iongirostris. B. fatalis was preponderant in central and eastern China, whereas B. longirostris was dominated in western China. The third lineage (B. hagmanni) was only detected in a reservoir (CJR) of eastern China (Guangdong province). Bosmina had limited distribution on the Tibetan plateau.
\end{abstract}

Conclusions: This study revealed that the biogeography of Bosmina appear to be affected by historical events (Pleistocene glaciations) and contemporary environment (such as altitude, eutrophication and isolated habitat).

Keywords: Bosmina, Distribution, Genetic investigation, China

\section{Background}

China is an important biogeographical zone, where the genetic legacies of the Tertiary and Quaternary periods are abundant. On the one hand, the region $\left(\sim 25-50^{\circ} \mathrm{N}\right)$ in the warm temperate-subtropical zone retained moderately high temperatures and provided a good shelter environment for endemics during Tertiary climatic changes $[1,2]$. On the other hand, the existence of different geographic refugia of Pleistocene (an era in the Quaternary period) did shelter varied lineages with diversity that are also

\footnotetext{
* Correspondence: wzwei@yzu.edu.cn

College of Animal Science and Technology, Yangzhou University, Yangzhou 225009, China
}

affected by vicariance processes and allopatric speciation $[3,4]$. At contemporary time, China, a vast territory with different North-South monsoons and East-West altitudes, has a complex geographic environment, the effect of which on the species distribution is also important. Therefore, many biogeographical studies have focused on the organisms of the region [5-8]. In particular, zooplankton, a group of freshwater invertebrate with a key role in the formation of biogeographical principles, attracted researchers' attention [9-11]. Previous genetic analyses have supported the generality of endemism and provincialism, and reinforced the need for detailed regional studies of zooplankton $[12,13]$. 
Species of the genus Bosmina Baird, 1845 (Anomopoda: Bosminidae) is small cladocerans (approximation 0.254 $0.319 \mathrm{~mm}$ ) that exist in lakes and reservoirs in every biogeographical region $[14,15]$. The genus not only purifies the water by the highly efficient filtration of bacteria, organic detritus and phytoplankton (top-down control) in the waterbodies, but also is rich in protein and fat, which can be used as bait for fish (bottom-up control). Therefore, Bosmina plays an important role in energy flow, the carbon cycle and the nutrient salt mineralization of waters [16]. Moreover, Bosmina may achieve high biomass under a variety of conditions that are unfavorable for other cladocerans. And its dominant position has become increasingly more apparent in recent decades [17]. Bosmina is also among the best preserved zooplankton in limnological sediments due to their robust carapace, making them ideal paleolimnological indicators of ecosystem change $[18,19]$.

Three species of this genus were reported in China based on a morphological study, including $B$. longirostris $\mathrm{O}$. F. Müller, 1785, B. coregoni Baird, 1857 and B. fatalis Burckhardt, 1924 [20]. Due to the phenotypic plasticity induced by biotic/abiotic signals and the intermediate hybrid morphology that is affected by introgression, assignment of taxa within the Bosmina based on the general phenotype is unreliable [21-23]. Fortunately, DNA sequencing of a standard gene region or "DNA barcoding" might speed a solution [24]. Recent studies based on DNA markers have contributed significantly in the resolution of taxonomic units within Bosmina and have allowed questions regarding the diversity and distribution of species to be readdressed in other Holarctic regions (mainly in Europe and in North America) [25, 26]. However, no genetic data are available to assess the biogeography of Bosmina in China, which is rich in endemics that are awaiting description [2].

In the present study, zooplankton samples were analyzed from 48 Chinese waterbodies (from 2 to $5135 \mathrm{~m}$ above sea level; from oligotrophic to eutrophic conditions), in which 35 populations of Bosmina was detected. Because the mtDNA gene (partial 16S rDNA, further abbreviated as 16S) is highly informative in biogeographic studies, and the nuclear gene region (internal transcribed spacer) is most informative for Bosmina that involve comparisons above the species level [19]. Both fragments were chosen as molecular markers to detect distribution of different lineages for Bosmina and to reveal the DNA molecular information of those lineages found in China.

\section{Methods}

\section{Sampling methodology}

Previous study showed that density of Bosmina is relatively high in summer and positively correlated with water temperature [27], so all samples were collected in summer (June, July and August) of 2016 across China. We sampled waterbodies to cover as much as possible in five major regions, which could fully represent different geographic and limnological types of waterbodies in China. Eastern Plain Region (EPR) is located in the middle and lower reaches of the Yangtze River, where most waterbodies have a high degree of eutrophication. Mongolia-Xinjiang Plateau (MXP) is located in arid and semiarid regions with a sandy/dusty weather and less precipitation. Northeast China region (NCR) is located in a humid and sub-humid area with a continental monsoon climate. Waterbodies in this region are rich in organic materials and humus in sediments. Yunnan-Guizhou Plateau (YGP) is located in the southwest of China, in a large karst area, and there are > 30 waterbodies with a low degree of eutrophication. Tibetan Plateau (QTP) is located at the highest altitude and is the most recently formed region, which is the least polluted area [28]. The sampling situation is as follows: nineteen of these waterbodies were located on the EPR, seven waterbodies were situated on the MXP, four waterbodies lied on the NCR, eight waterbodies were seated on the YGP, and ten remaining waterbodies were distributed on QTP (Table 1).

\section{Environmental variables}

Several variables were measured in situ: the sampling position (Latitude, Longitude and Altitude) was recorded with GPS-S6 (Newsmy), Secchi disk visibility (SD) was determined with a Secchi disk M369488 (Beijing Zhongxiyuanda Technology Co., LTD), and water temperature (WT) was measured using FG4-FK (Mettler Toledo Co., Greifensee, Switzerland). Water samples were collected with a Van Dorn bottle for subsequent laboratory analyses of total phosphorus (TP) concentrations, and chlorophyll-a (Chl. a) according to the methods described in detail by Huang [29]. Using the values of SD, TP, and Chl a, a classic trophic state index for waterbodies is calculated to characterize the trophic level of the sampled sites [30].

\section{Zooplankton sampling}

Zooplankton samples were collected (Additional file 1: Tables S1, S2 and Fig. 1) with a 125-mm plankton net hauled through the whole water column at three different sites per waterbody within the deep basin or from the shore; these samples were later pooled and preserved in $95 \%$ ethanol for further analyses. By using a stereomicroscope, Bosmina was found in 35 waterbodies and ten adult females were selected per waterbody for genetic analyses.

\section{Molecular analysis}

DNA of the Bosmina specimens was extracted by the proteinase $\mathrm{K}$ method [31] and stored at $-4{ }^{\circ} \mathrm{C}$. Each 50- $\mu \mathrm{l}$ polymerase chain reaction (PCR) consisted of $40 \mu \mathrm{l}$ irradiated $\mathrm{H}_{2} \mathrm{O}, 5 \mu \mathrm{l} 10 \times$ PCR buffer, $1.5 \mathrm{mM} \mathrm{MgCl}_{2}, 2$ $\mathrm{mM}$ of each dNTP, $1 \mu \mathrm{M}$ of each primer, $0.5-1$ units Taq 
Table 1 Environmental variables of the studied waterbodies

\begin{tabular}{|c|c|c|c|c|c|c|c|c|c|}
\hline Waterbody name (abbreviation) & $\begin{array}{l}\text { Latitude } \\
(\mathrm{N})\end{array}$ & $\begin{array}{l}\text { Longitude } \\
\text { (E) }\end{array}$ & $\begin{array}{l}\text { Altitude } \\
\text { (m) }\end{array}$ & $\begin{array}{l}\text { WT } \\
\left({ }^{\circ} \mathrm{C}\right)\end{array}$ & $\begin{array}{l}\text { SD } \\
(\mathrm{m})\end{array}$ & $\begin{array}{l}\mathrm{TP} \\
\left(\mu \mathrm{g} \mathrm{L}^{-1}\right)\end{array}$ & $\begin{array}{l}\text { Chl. a } \\
\left(\mathrm{mg} \mathrm{L}^{-1}\right)\end{array}$ & T.S.I. & Trophic level \\
\hline \multicolumn{10}{|l|}{ Eastern Plain Region (EPR) } \\
\hline Chao Lake (CAH) & 31.43 & 117.22 & 10 & $26.6 \pm 1.42$ & $0.75 \pm 1.17$ & $80.15 \pm 2.59$ & $4.76 \pm 0.59$ & 67.77 & Eutro \\
\hline Changjiang Reservoir (CJR) & 22.29 & 113.26 & 24 & $26.4 \pm 1.48$ & $0.68 \pm 0.57$ & $54.15 \pm 0.60$ & $4.46 \pm 0.23$ & 55.90 & Eutro \\
\hline Dong Lake (DOH) & 30.33 & 114.24 & 39 & $24.9 \pm 3.69$ & $0.63 \pm 1.63$ & $72.77 \pm 0.17$ & $4.79 \pm 0.73$ & 61.26 & Eutro \\
\hline Dongping Lake (DPH) & 35.59 & 116.12 & 41 & $18 \pm 3.34$ & $0.62 \pm 3.89$ & $69.10 \pm 0.88$ & $4.64 \pm 1.76$ & 59.18 & Eutro \\
\hline Dongting Lake (DTH) & 29.22 & 113.05 & 27 & $18.7 \pm 5.49$ & $0.7 \pm 1.70$ & $82.03 \pm 0.97$ & $3.07 \pm 0.24$ & 61.23 & Eutro \\
\hline Gaoyou Lake (GYH) & 32.52 & 119.24 & 5 & $26.8 \pm 1.65$ & $0.77 \pm 0.95$ & $66.63 \pm 2.72$ & $3.68 \pm 0.54$ & 60.27 & Eutro \\
\hline Hongze Lake (HZH) & 33.26 & 118.15 & 10 & $25.5 \pm 4.09$ & $0.76 \pm 1.70$ & $75.85 \pm 2.23$ & $3.80 \pm 3.22$ & 63.45 & Eutro \\
\hline Luhun Reservoir (LHR) & 34.22 & 112.01 & 540 & $23.6 \pm 3.72$ & $0.32 \pm 2.40$ & $50.00 \pm 0.67$ & $3.45 \pm 3.04$ & 38.89 & Oligo \\
\hline Luo Lake (LUH) & 32.33 & 109.12 & 17 & $19.6 \pm 4.50$ & $0.63 \pm 0.25$ & $59.07 \pm 85.08$ & $1.02 \pm 19.21$ & 44.43 & Oligo/Meso \\
\hline Luoma Lake (LMH) & 34.00 & 118.15 & 17 & $28.6 \pm 3.97$ & $0.6 \pm 0.60$ & $71.15 \pm 8.77$ & $3.51 \pm 5.11$ & 55.56 & Eutro \\
\hline Poyang Lake (PYH) & 29.26 & 116.00 & 17 & $25.5 \pm 4.92$ & $0.61 \pm 1.66$ & $60.86 \pm 3.13$ & $4.84 \pm 0.31$ & 57.04 & Eutro \\
\hline Qiandao Lake (QDH) & 29.4 & 119.05 & 600 & $23.8 \pm 4.15$ & $0.4 \pm 2.33$ & $75.55 \pm 1.90$ & $4.85 \pm 1.03$ & 54.76 & Eutro \\
\hline Songtao Reservoir (STR) & 19.24 & 109.33 & 165 & $23.9 \pm 4.32$ & $0.5 \pm 1.06$ & $73.81 \pm 0.38$ & $4.71 \pm 0.78$ & 57.09 & Eutro \\
\hline Tai Lake (TAH) & 31.29 & 120.07 & 2 & $26.6 \pm 4.09$ & $0.76 \pm 0.92$ & $71.57 \pm 0.25$ & $3.47 \pm 0.22$ & 60.91 & Eutro \\
\hline Xiliang Lak (XLH) & 29.55 & 114.03 & 16 & $21.5 \pm 4.66$ & $0.64 \pm 0.85$ & $74.57 \pm 1.13$ & $3.91 \pm 0.61$ & 59.47 & Eutro \\
\hline Xinfengjiang Reservoir (XFJR) & 23.43 & 114.38 & 119 & $23.8 \pm 4.78$ & $0.38 \pm 0.78$ & $80.04 \pm 3.12$ & $4.37 \pm 2.09$ & 54.15 & Eutro \\
\hline Ying Lake $(\mathrm{YIH})$ & 32.63 & 108.79 & 515 & $23.3 \pm 3.64$ & $0.77 \pm 0.21$ & $62.22 \pm 1.73$ & $3.80 \pm 0.75$ & 59.22 & Eutro \\
\hline \multicolumn{10}{|l|}{ Mongolia-Xinjiang Plateau (MXP) } \\
\hline Bositeng Lake (BSTH) & 41.54 & 86.44 & 1048 & $23.6 \pm 3.68$ & $0.5 \pm 0.14$ & $47.37 \pm 0.95$ & $1.10 \pm 0.35$ & 36.24 & Oligo \\
\hline Hulun Lake (HLH) & 49.19 & 117.38 & 539 & $22.1 \pm 5.73$ & $0.73 \pm 1.10$ & $78.83 \pm 0.89$ & $1.70 \pm 1.84$ & 56.38 & Eutro \\
\hline Hasuhai Lake (HSH) & 40.71 & 111.01 & 988 & $21.3 \pm 6.00$ & $0.61 \pm 0.49$ & $73.69 \pm 4.57$ & $3.84 \pm 0.16$ & 57.84 & Eutro \\
\hline Kundulun Lake (KDLH) & 40.78 & 109.78 & 1067 & $22.3 \pm 5.86$ & $0.61 \pm 4.63$ & $40.00 \pm 4.07$ & $1.07 \pm 2.39$ & 37.46 & Oligo \\
\hline Liujiaxia Reservoir (LJXR) & 35.56 & 103.19 & 1731 & $16.6 \pm 5.83$ & $0.62 \pm 3.04$ & $56.24 \pm 2.27$ & $1.02 \pm 0.67$ & 43.00 & Oligo \\
\hline TianChi (TIC) & 43.53 & 88.07 & 1928 & $22.9 \pm 3.25$ & $0.43 \pm 0.71$ & $46.63 \pm 2.89$ & $1.10 \pm 0.86$ & 33.56 & Oligo \\
\hline Wulungu Lake (WLGH) & 47.00 & 87.2 & 478 & $22.0 \pm 3.17$ & $0.55 \pm 1.13$ & $50.00 \pm 1.00$ & $1.84 \pm 0.57$ & 41.40 & Oligo \\
\hline \multicolumn{10}{|l|}{ Northeast China Region (NCR) } \\
\hline Chagan Lake (CGH) & 45.12 & 124.25 & 126 & $13.4 \pm 6.29$ & $0.77 \pm 0.39$ & $73.46 \pm 4.11$ & $2.79 \pm 0.38$ & 59.76 & Eutro \\
\hline Erlongshan Reservoir (ELSR) & 45.43 & 127.24 & 720 & $24.7 \pm 6.93$ & $0.59 \pm 0.28$ & $60.00 \pm 0.90$ & $4.77 \pm 0.64$ & 55.87 & Eutro \\
\hline Songhua Lake (SHH) & 43.39 & 126.46 & 261 & $29.8 \pm 2.57$ & $0.46 \pm 0.18$ & $77.99 \pm 7.06$ & $4.22 \pm 0.08$ & 55.47 & Eutro \\
\hline \multicolumn{10}{|l|}{ Yunnan-Guizhou Plateau (YGP) } \\
\hline Ahang Reservoir (AHR) & 26.32 & 106.39 & 1027 & $21.2 \pm 2.45$ & $0.6 \pm 0.42$ & $54.59 \pm 1.14$ & $4.66 \pm 0.76$ & 54.04 & Eutro \\
\hline Changshou Lake (CSH) & 29.55 & 107.14 & 329 & $14.4 \pm 8.63$ & $0.62 \pm 0.25$ & $76.15 \pm 6.44$ & $2.69 \pm 1.92$ & 55.13 & Eutro \\
\hline Dianchi (DIC) & 24.57 & 102.4 & 1886 & $22.9 \pm 9.50$ & $0.76 \pm 0.25$ & $93.56 \pm 17.61$ & $4.37 \pm 2.17$ & 71.11 & Eutro \\
\hline Fuxian Lake (FXH) & 24.53 & 102.83 & 1722 & $21.8 \pm 1.34$ & $0.33 \pm 2.17$ & $30.00 \pm 1.59$ & $3.51 \pm 2.03$ & 32.88 & Oligo \\
\hline Hongfeng Lake (HFH) & 26.32 & 106.25 & 1240 & $28.2 \pm 2.14$ & $0.61 \pm 1.95$ & $75.56 \pm 1.88$ & $3.37 \pm 0.84$ & 56.77 & Eutro \\
\hline Heilongtan Reservoir (HLTR) & 30.02 & 104.03 & 568 & $26.8 \pm 5.18$ & $0.54 \pm 2.66$ & $72.35 \pm 1.89$ & $3.57 \pm 2.57$ & 54.22 & Eutro \\
\hline Sancha Reservoir (SCR) & 30.18 & 104.16 & 457 & $20.2 \pm 3.55$ & $0.64 \pm 2.10$ & $74.15 \pm 1.90$ & $3.43 \pm 1.38$ & 57.56 & Eutro \\
\hline Yecheng Lake (YCH) & 30.54 & 103.33 & 1600 & $23.1 \pm 4.72$ & $0.67 \pm 3.63$ & $63.92 \pm 1.06$ & $1.05 \pm 2.92$ & 47.20 & Meso \\
\hline
\end{tabular}




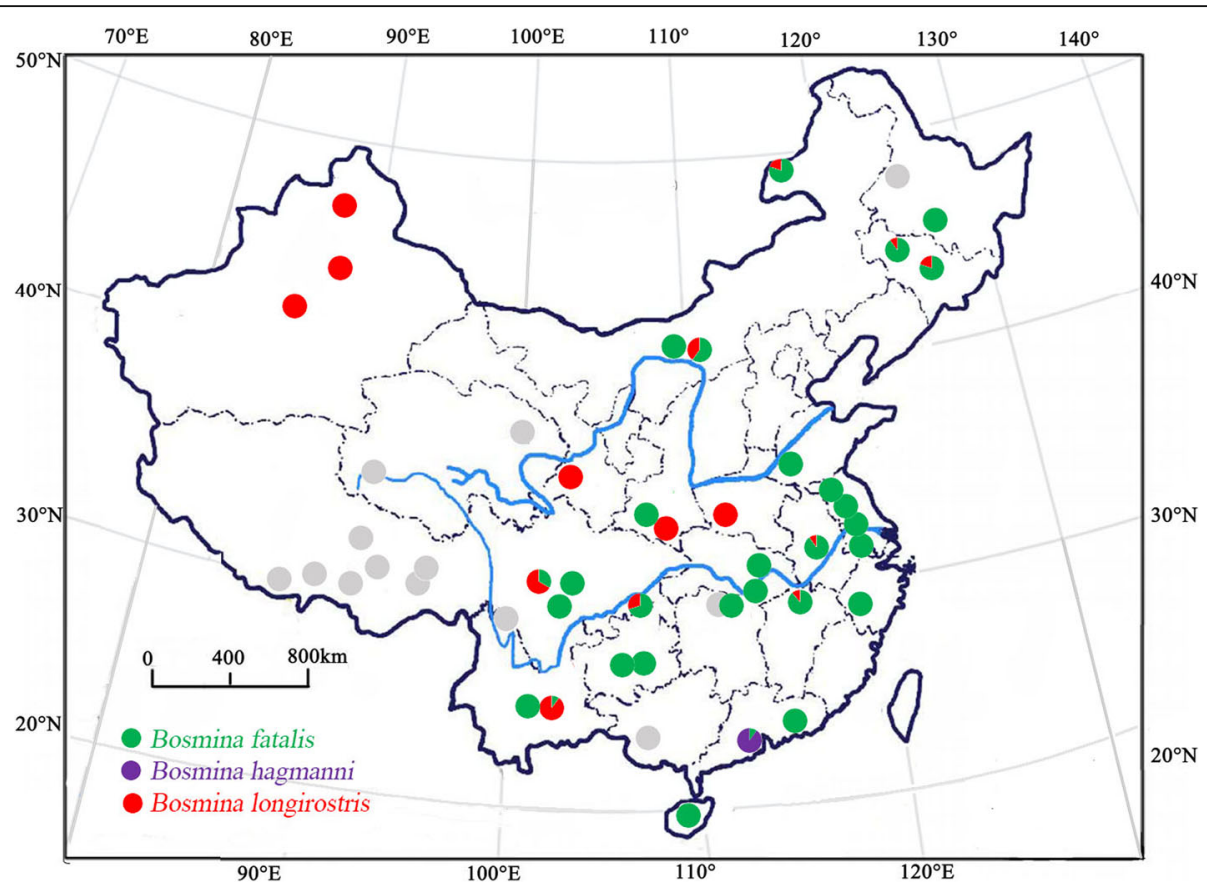

Fig. 1 Geographic location of collection sites for Bosmina. Color dots: waterbodies inhabited with the Bosmina; gray dots: Bosmina was not detected. Species proportion in 35 sampled populations illustrated as a pie chart (Additional file 1: Table S1). Green symbols: B. fatalis; purple symbols: B. hagmanni; red symbols: B. longirostris. Taxon identification is based on 165 and ITS sequence variation

DNA polymerase, and 1/10th DNA extract. The primers and PCR temperature profiles of the $16 \mathrm{~S}$ and ITS followed those of a previous study [19]. Next, the PCR products were purified and sequenced in the forward direction on an ABI PRISM 3730 DNA capillary sequencer by Invitrogen Trading Co., Ltd. (China). The chromatograms were carefully checked for scoring errors.

\section{Sequence alignment}

Sequences of the target individuals were aligned with reference species (Additional file 1: Tables S1 and S3) using the Clustal W algorithm [32] at locus $16 \mathrm{~S}$ and ITS in MEGA.7 [33]. The genera of Bosminopsis and Ilyocryptus are distantly related to Bosmina; thus, the level of divergence between them could lead to an alignment error, long-branch attraction bias and incorrect model estimation. Therefore, in this study, model parameters and phylogenetic trees with in-group taxa only were estimated as suggested by Taylor et al. (2002) [19].

\section{Phylogeny}

The phylogenetic relationships among lineages were visualized for both the $16 \mathrm{~S}$ and ITS datasets. In cases where several individuals carried an identical haplotype, only one was included subsequently. First, the best-fit for both datasets (16S: GTR + G + I and ITS: GTR + G) were identified by jModelTest version 2.1.3 [34], and we then applied these models to run the maximum likelihood (ML) analysis in RAxML [35]. The assignment of species identity (or genetic lineage) of studied individuals was based on clustering with reference sequences in the phylogenetic trees, which was supported by 1000 bootstrapping. All subsequent calculations were based on the taxonomic units that were thereby defined.

\section{Genetic polymorphism and differentiation}

The followed analyses were based on data (Additional file 1: Table S1) to learn the genetic polymorphism of two main lineages (i.e. B. fatalis and B. longirostris) found in this study (Fig. 1). In DnaSP v5, haplotype diversity $(H d)$ and nucleotide diversity $(\mathrm{Pi})$ were calculated for the $16 \mathrm{~S}$ (249 individuals) and the ITS (305 individuals) genes of main lineages, to determine the level of sequence diversity within the Bosmina [36]. Because $16 \mathrm{~S}$ is more highly informative for biogeographic studies within species than ITS [19], we calculated $p$-distances (in MEGA.7) of $16 \mathrm{~S}$ among all the geographical populations for B. fatalis and $B$. longirostris respectively, plus standard error calculated on 1000 bootstrap replicates [33]. In addition, the pairwise genetic differentiation of $16 \mathrm{~S}$ among geographical populations was estimated (in Arlequin v. 3.11) using the fixation index Fst, which included information on mitochondrial haplotype frequency and genetic distances. The 
significance was tested by 1000 permutations for each pairwise comparison [37].

\section{Haplotype network}

To describe the intraspecific variation and relationships among populations from different regions, two haplotype networks (16S and ITS) were constructed based on previous and our studies (Additional file 1: Tables S1 and S3) by HapView with the input of maximum-likelihood trees [38].

\section{Results}

\section{Environmental data}

Among the 35 sampling sites where Bosmina found, most central and eastern waterbodies (15 of EPR, 2 of MXP, 3 of NCR and 6 of YGP) usually have very high trophic levels, while western waterbodies (2 of EPR, 5 of MXP and 2 of YGP) are mesotrophic or oligotrophic (Table 1).

\section{Phylogeny and distribution}

Altogether, 249 individuals were successfully sequenced at the $16 \mathrm{~S}$ locus, and 305 were sequenced at the ITS region (because of a failure in either amplification or sequencing; Table 1). Among these individuals, 17 unique 16S haplotypes and 12 unique ITS haplotypes were found (Additional file 1: Table S1). Phylogenetic analysis revealed that 291 out of 305 Bosmina individuals sampled in this study definitely belong to two species clades: $B$. fatalis and B. longirostris. Moreover, one subclade (with 5 individuals) was detected from $B$. fatalis and another ( 9 individuals) from the species of $B$. hagmanni (Figs. 2 and 3, Additional file 1: Table S1).

The Bosmina detected in China had different geographic distributions: $B$. fatalis was present in eutrophic waterbodies from central and eastern China, whereas $B$. longirostris was dominant in oligotrophic/mesotrophic waterbodies of the western region (Table 1 and Fig. 1). The lineage close to $B$. fatalis was distributed in four waterbodies, including $\mathrm{CAH}, \mathrm{CJR}, \mathrm{DOH}$ and $\mathrm{PYH}$. The lineage close to $B$. hagmanni was rarely present in China from this study and was only detected in a reservoir (CJR) of the Guangdong province (Fig. 1 and Additional file 1: Table S1). No Bosmina was detected in 10 waterbodies on the Tibetan Plateau, indicating its limited distribution in the region (Fig. 1 and Additional file 1: Table S2).

\section{Genetic polymorphism and differentiation}

The level of nucleotide polymorphism within B. fatalis was lower than $B$. longirostris at the $16 \mathrm{~S}$. However, this was not the case for the ITS, for which the level of nucleotide polymorphism between the two species was comparable (Table 2). The pairwise $p$-distance showed that most population of $B$. fatalis had lower differentiation than $B$. longirostris. In addition, most of the Fst population pairwise comparisons of $B$. fatalis were low and not significant. However, values of Fst in $B$. longirostris were generally high and most significant Fst values $(p<0.05)$ were included. The different Fst also displayed the different differentiation within $B$. fatalis and B. longirostris (Tables 3 and 4).

\section{Haplotype network}

The haplotypes of $B$. fatalis were restricted to eastern Asia (central and eastern China; Japan). In contrast, those of $B$. longirostris were widely distributed in other Holarctic regions (China, Denmark, Germany, Russia, Japan and the USA) (Figs. 4 and 5).

The 16S haplotype network of $B$. fatalis was arranged in a star-like pattern with a dominating haplotype (i.e., $a$ ) that was shared by 24 waterbodies, including $\mathrm{CAH}, \mathrm{DTH}$, GYH, HZH, LMH, PYH, QDH, STR, TAH, XLH, XFJR, YIH, HLH, HSH, CGH, ELSR, SHH, AHR, CSH, FXH, HFH, HLTR, SCR and YCH (waterbodies abbreviation were shown in Table 1). The $16 \mathrm{~S}$ haplotype network of $B$. longirostris showed five shared haplotypes (i.e., $b, c, d, e$, f). $\mathrm{CNm} 5$ (e) was the most quantitatively frequent haplotype of $B$. longirostris and was shared by three waterbodies (BSTH, TIC and WLGH). The second-most frequent haplotypes were $\mathrm{CNm} 3$ (c) and $\mathrm{CNm} 4$ (d), which were found in four waterbodies (DPH, LHR, LUH and KDLH) and in five waterbodies (DPH, LUH, HSH, LJXR, and FXH), respectively (Fig. 4 and Additional file 1: Table S1).

The ITS haplotype network showed that Bosmina had the two $(i$ and $h)$ most abundant haplotypes. B. fatalis (i) was shared by 26 waterbodies $(\mathrm{CAH}, \mathrm{DOH}, \mathrm{DTH}, \mathrm{GYH}$, HZH, LMH, PYH, QDH, STR, TAH, XLH, XFJR, YIH, HLH, HSH, CGH, ELSR, SHH, AHR, CSH, DIC, FXH, $\mathrm{HFH}, \mathrm{HLTR}, \mathrm{SCR}$, and $\mathrm{YCH}$ ) and $B$. longirostris (h) was found in 17 waterbodies $(\mathrm{CAH}, \mathrm{DPH}, \mathrm{LHR}, \mathrm{LUH}, \mathrm{PYH}$, BSTH, HLH, HSH, KDLH, LJXR, TIC, WLGH, ELSR, $\mathrm{SHH}, \mathrm{CSH}, \mathrm{FXH}$, and $\mathrm{YCH})$. In particular, B. longirostris (h), presented a frequently shared ITS haplotype with several haplotypes surrounded, showed the lower variation compared with $16 \mathrm{~S}$ network (Fig. 5 and Additional file 1: Table S1).

\section{Discussion}

\section{Different spatial pattern of $B$. fatalis and $B$. longirostris}

Our phylogenetic analysis and network showed that the Chinese B. fatalis were closely related to those in Japan, confirming B. fatalis (also known as Sinobosmina fatalis) is endemic in Eastern Asia [39]. It has been early recognized that endemic taxa are not randomly distributed. Range restriction as a consequence of survival in refugia has been regarded as a driving force generating distributional patterns of endemics [12]. East Asia has been recognized as a major glacial Pleistocene refugium [40], where several new endemic cladocerans have found in 


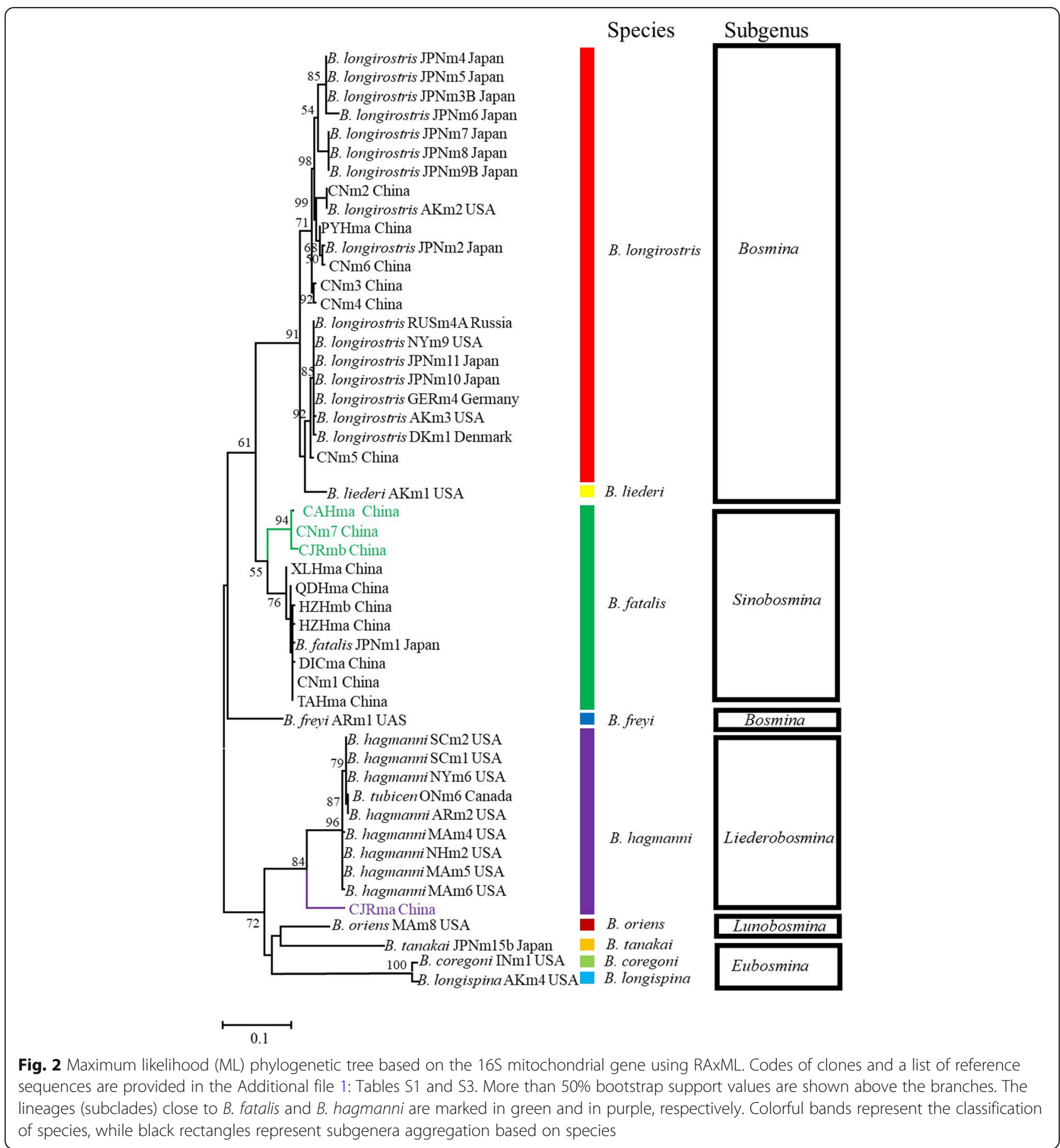

Japan and neighboring areas $[23,41]$. It seems that the endemism of $B$. fatalis is also a result of survival in refugia. The waves of Pleistocene glaciation, resulted in mass extinction of biotas in many region [1], while East Asia region remained comparatively unchanged [40]. Therefore, B. fatalis may survive in this region until now. In addition, the vicariance effects of the Pleistocene glaciations have played a major role in shaping the intraspecific divergence of freshwater zooplankton [12]. A lineage close to $B$. fatalis found in only four waterbodies (CAH, CJR, DOH and PYH) may be a geographically isolated species differentiated from $B$. fatalis.

Some cladocerans, such as $B$. fatalis, may be relicts with restricted-range (endemic), whereas others, commonly and widely distributed within their extensive primary ranges, possiblely are not [2]. We found close relatives among B. longirostris lineages from China, Denmark, Germany, Russia, Japan and the USA, which 


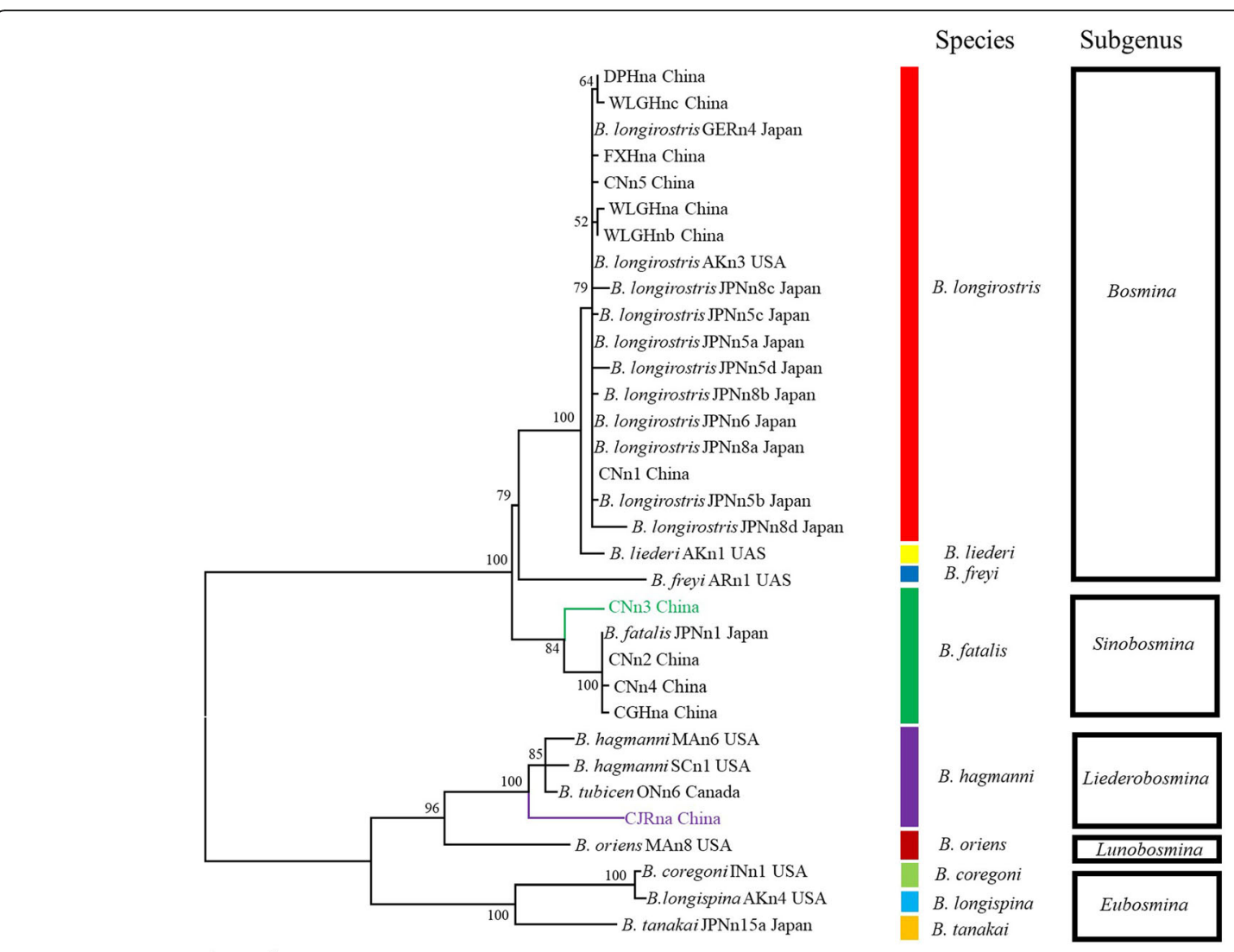

Fig. 3 Maximum likelihood (ML) phylogenetic tree based on ITS nuclear gene using RAxML. Codes of clones and a list of reference sequences are provided in the Additional file 1: Tables S1 and S3. More than 50\% bootstrap support values are shown above the branches. The lineages (subclades) close to B. fatalis and B. hagmanni are marked in green and in purple, respectively. Colorful bands represent the classification of species, while black rectangles represent subgenera aggregation based on species

suggested that $B$. longirostris is widespread in the Holarctic region [42]. Therefore, $B$. longirostris should be an advanced lineage and have a non-relict status, which affected by current climate [43]. In all, the different spatial patterns of $B$. fatalis and B. longirostris can be explained by their different evolutionary status (relict and non-relict).

\section{Genetic polymorphism of $B$. fatalis and $B$. longirostris}

Due to small population size and past bottlenecks, many relicts tend to have low within-population genetic polymorphism [44, 45]. Accordingly, the lower nucleotide diversity of $B$. fatalis than $B$. longirostris at $16 \mathrm{~S}$ locus could be another evidence of their different evolutionary status

Table 2 Genetic diversity within Chinese samples from the Bosmina

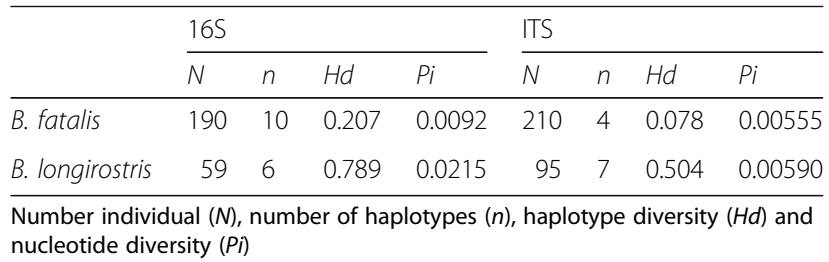

(Table 2). Also, homogenization of refugial population after glaciation is unlikely in water fleas because they should possess pronounced refugial inertia. That is, successful colonization of an occupied water body is theoretically very difficult because of the strong priority effects from rapid lake-specific selection, massive egg banks and large existing populations [26]. The effect can essentially extend the time of genetic isolation of refugia even in the face of dispersal [46]. This may be why their difference of nucleotide diversity at $16 \mathrm{~S}$ locus have been preserved to the present. Furthermore, this refugial inertia could provide more time for reproductive isolation [26]. Therefore, after thousands of years of unglaciated conditions, B. fatalis seems remain distinct and did not hybridize with $B$. longirostris, although they co-occur in some waterbodies (Fig. 1).

However, as a non-coding sequence which do not involve in the formation of the ribosome, ITS have small selective pressure and high divergent rate. For example, ITS evolution rate is 2.5 times of mitochondrial gene (COI) in Tetranychus [47] and 2 times of rDNA in Nasonia [48]. In this study, the nucleotide diversity for $B$. fatalis is similar to this index for B. longirostris at the 
Table 3 Genetic distance ( $p$-distance: upper diagonal) and the fixation index considering genetic distances (Fst: lower diagonal) among 27 geographical populations of $B$. fatalis in China

\begin{tabular}{|c|c|c|c|c|c|c|c|c|c|c|c|c|c|c|c|c|c|c|c|c|c|c|c|c|c|c|c|}
\hline & $\mathrm{CAH}$ & $\mathrm{C} J \mathbb{R}$ & $\mathrm{DOH}$ & DTH & GYH & $\mathrm{HZH}$ & LMH & PYH & QDH & STR & TAH & $\mathrm{XLH}$ & XFJR & YIH & HLH & HSH & $\mathrm{CGH}$ & ELSR & SHH & AHR & $\mathrm{CSH}$ & DIC & FXH & $\mathrm{HFH}$ & HLTR & SCR & $\mathrm{YCH}$ \\
\hline $\mathrm{CAH}$ & & 0.037 & 0.033 & 0.009 & 0.009 & 0.009 & 0.009 & 0.012 & 0.009 & 0.009 & 0.009 & 0.009 & 0.009 & 0.009 & 0.009 & 0.009 & 0.009 & 0.009 & 0.009 & 0.009 & 0.009 & 0.009 & 0.009 & 0.009 & 0.009 & 0.009 & 0.013 \\
\hline $\mathrm{CJR}$ & 0.611 & & 0.007 & 0.046 & 0.046 & 0.046 & 0.046 & 0.040 & 0.046 & 0.046 & .046 & 0.046 & .046 & 0.046 & 0.046 & 0.046 & 0.046 & 0.046 & 0.046 & 0.046 & 0.046 & 0.046 & 0.046 & 0.046 & 0.046 & 0.046 & .050 \\
\hline $\mathrm{DOH}$ & 0.611 & 1.000 & & 0.041 & 041 & 0.042 & .041 & 0.035 & 042 & 041 & 041 & 0.041 & 041 & 0.041 & .041 & .041 & 0.041 & .041 & .041 & .041 & 0.041 & .041 & 0.041 & 0.041 & 41 & 041 & \\
\hline DTH & 0.107 & 1.000 & 1.000 & & 0.000 & .001 & .000 & 0.006 & 000 & 000 & 000 & 0.001 & 000 & 0.000 & .000 & 0.000 & .000 & .000 & 0.000 & .000 & .000 & .000 & 100 & 000 & 00 & 000 & \\
\hline GYH & 0.107 & 1.000 & 1.000 & 0.000 & & 0.001 & 0.000 & 0.006 & 0.000 & 0.000 & 0.000 & 0.001 & 0.000 & 0.000 & .000 & 0.000 & 0.000 & 0.000 & 0.000 & 0.000 & 0.000 & 0.000 & 0.000 & 0.000 & 0.000 & 0.000 & 04 \\
\hline $\mathrm{HZH}$ & 0.034 & 0.393 & 0.393 & 0.190 & 0.190 & & 0.001 & 0.007 & 0.001 & 0.001 & 0.001 & 0.002 & 0.001 & 0.001 & 0.001 & 0.001 & 0.001 & 0.001 & 0.001 & 0.001 & 0.001 & 0.001 & 0.001 & 0.001 & 0.001 & 0.001 & 0.005 \\
\hline LMH & 0.107 & 1.000 & 1.000 & 0.000 & 0.000 & 0.190 & & 0.006 & 0.000 & 0.000 & 0.000 & 0.001 & 0.000 & 0.000 & 0.000 & 0.000 & 0.000 & 0.000 & 0.000 & 0.000 & 0.000 & 0.000 & 0.000 & 0.000 & 0.000 & 0.000 & 0.004 \\
\hline PYH & -0.017 & 0.714 & 0.667 & 0.020 & 0.020 & 0.031 & 0.020 & & 0.006 & 0.006 & 0.006 & 0.007 & 0.006 & 0.006 & 0.006 & 0.006 & 0.006 & 0.006 & 0.006 & 0.006 & 0.006 & 0.006 & 0.006 & 0.006 & 0.006 & 0.006 & 0.010 \\
\hline QDH & -0.017 & 0.714 & 0.714 & 0.020 & 0.020 & 0.031 & 0.020 & -0.077 & & 0.000 & 0.001 & 0.001 & 0.000 & 0.000 & 0.000 & 0.000 & 0.000 & 0.000 & 0.000 & 0.000 & 0.000 & 0.000 & 0.000 & 0.000 & 0.000 & 0.000 & 0.005 \\
\hline STR & 0.107 & $1.000^{*}$ & 1.000 & 0.000 & 0.000 & 0.190 & 0.000 & 0.020 & 0.020 & & 0.000 & 0.001 & 0.000 & 0.000 & 0.000 & 0.000 & 0.000 & 0.000 & 0.000 & 0.000 & 0.000 & 0.000 & 0.000 & 0.000 & 0.000 & 0.000 & 0.004 \\
\hline TAH & 003 & 0.750 & 0.750 & 0.000 & 0.000 & 0.054 & 0.000 & -0.070 & -0.070 & 0.000 & & 0.001 & 0.000 & 0.000 & 0.000 & 0.000 & 0.000 & 0.000 & 0.000 & 0.000 & 0.000 & 0.000 & 0.000 & 0.000 & 0.000 & .000 & 0.005 \\
\hline $\mathrm{XLH}$ & -0.031 & 0.667 & 0.667 & 0.051 & 0.051 & 0.006 & 0.051 & -0.082 & -0.082 & 0.051 & -0.071 & & 0.001 & 0.001 & 0.001 & 0.001 & 0.001 & 0.001 & 0.001 & 0.001 & 0.001 & 0.001 & 0.001 & 0.001 & 0.001 & 0.001 & 0.005 \\
\hline XFJR & 0.063 & 1.000 & 1.000 & 0.000 & 0.000 & 0.140 & 0.000 & -0.024 & -0.024 & 0.000 & -0.040 & 0.000 & & 0.000 & 0.000 & 0.000 & 0.000 & 0.000 & 0.000 & 0.000 & 0.000 & 0.000 & 0.000 & 0.000 & 0.000 & 0.000 & 0.004 \\
\hline YIH & 0.087 & 1.000 & 1.000 & 0.000 & 0.000 & 0.167 & 0.000 & 0.000 & 0.000 & 0.000 & -0.018 & 0.028 & 0.000 & & 0.000 & 0.000 & 0.000 & 0.000 & 0.000 & 0.000 & 0.000 & 0.000 & 0.000 & 0.000 & 0.000 & 0.000 & 0.004 \\
\hline $\mathrm{HLH}$ & -0.068 & 1.000 & 1.000 & 0.000 & 0.000 & 0.002 & 0.000 & -0.167 & -0.167 & 0.000 & -0.175 & -0.154 & 0.000 & 0.000 & & 0.000 & 0.000 & 0.000 & 0.000 & 0.000 & 0.000 & 0.000 & 0.000 & 0.000 & 0.000 & 0.000 & 0.004 \\
\hline HSH & -0.068 & 1.000 & 1.000 & 0.000 & 0.000 & 0.002 & 0.000 & -0.167 & -0.167 & 0.000 & -0.175 & -0.154 & 0.000 & 0.000 & 0.000 & & 0.000 & 0.000 & 0.000 & 0.000 & 0.000 & 0.000 & 0.000 & 0.000 & 0.000 & 0.000 & 0.004 \\
\hline $\mathrm{CGH}$ & 0.087 & 1.000 & 1.000 & 0.000 & 0.000 & 0.167 & .000 & 0.000 & 0.000 & 000 & -0.018 & 0.028 & 0.000 & 0.000 & 0.000 & 0.000 & & 0.000 & 0.000 & 0.000 & 0.000 & 0.000 & 0.000 & 0.000 & 0.000 & 0.000 & 0.004 \\
\hline ELSR & 0.063 & 1.000 & 1.000 & 0.000 & 0.000 & 0.140 & 0.000 & -0.024 & -0.024 & 0.000 & -0.040 & 0.000 & 0.000 & 0.000 & 0.000 & 0.000 & 0.000 & & 0.000 & 0.000 & 0.000 & 0.000 & 0.000 & 0.000 & 0.000 & 0.000 & 0.004 \\
\hline $\mathrm{SHH}$ & 0.087 & 1.000 & 1.000 & 0.000 & 0.000 & 0.167 & 0.000 & 0.000 & 0.000 & 0.000 & -0.018 & 0.028 & 0.000 & 0.000 & 0.000 & 0.000 & 0.000 & 0.000 & & 0.000 & 0.000 & 0.000 & 0.000 & 0.000 & 0.000 & 0.000 & 0.004 \\
\hline AHR & 0.125 & 1.000 & 1.000 & 0.000 & 0.000 & 0.211 & 0.000 & 0.038 & 0.038 & 0.000 & 0.016 & 0.072 & 0.000 & 0.000 & 0.000 & 0.000 & 0.000 & 0.000 & 0.000 & & 0.000 & 0.000 & 0.000 & 0.000 & 0.000 & 0.000 & 0.004 \\
\hline $\mathrm{CSH}$ & 0.063 & $1.000^{*}$ & 1.000 & 0.000 & 0.000 & 0.140 & 0.000 & -0.024 & -0.024 & 0.000 & -0.040 & 0.000 & 0.000 & 0.000 & 0.000 & 0.000 & 0.000 & 0.000 & 0.000 & 0.000 & & 0.000 & 0.000 & 0.000 & 0.000 & 0.000 & 0.004 \\
\hline DIC & $0.795^{*}$ & 1.000 & 1.000 & $1.000^{*}$ & $1.000^{*}$ & $0.696^{*}$ & $1.000^{*}$ & $0.867^{*}$ & $0.867 *$ & $1.000 *$ & $0.875^{*}$ & $0.858 *$ & $1.000^{*}$ & $1.000^{*}$ & $1.000 *$ & $1.000^{*}$ & $1.000^{*}$ & $1.000 *$ & $1.000 *$ & $1.000 *$ & $1.000^{*}$ & & 0.000 & 0.000 & 0.000 & 0.000 & 0.004 \\
\hline FXH & -0.750 & 1.000 & 1.000 & 0.000 & 0.000 & -0.619 & 0.000 & -1.000 & -1.000 & 0.000 & -1.000 & -1.000 & 0.000 & 0.000 & 0.000 & 0.000 & 0.000 & 0.000 & 0.000 & 0.000 & 0.000 & 1.000 & & 0.000 & 0.000 & 0.000 & 0.004 \\
\hline $\mathrm{HFH}$ & 0.141 & 1.000 & 1.000 & 0.000 & 0.000 & 0.230 & 0.000 & 0.054 & 0.054 & 0.000 & 0.029 & 0.091 & 0.000 & 0.000 & 0.000 & 0.000 & 0.000 & 0.000 & 0.000 & 0.000 & 0.000 & $1.000^{*}$ & 0.000 & & 0.000 & 0.000 & 0.004 \\
\hline HLTR & 141 & 1.000 & 1.000 & 0.000 & 0.000 & $0.230 *$ & 0.000 & 0.054 & 0.054 & 0.000 & 0.0 & 0.091 & 0.000 & 0.000 & .000 & .000 & 0.000 & 0.000 & 0.000 & 0.000 & 0.000 & $1.000 *$ & 0.000 & 0.000 & & 0.000 & 0.004 \\
\hline SCR & 0.125 & 1.000 & 1.000 & 0.000 & 0.000 & 0.211 & 0.000 & 0.038 & 0.038 & 0.000 & 0.016 & 0.072 & 0.000 & 0.000 & 0.000 & 0.000 & 0.000 & 0.000 & 0.000 & 0.000 & 0.000 & $1.000^{*}$ & 0.000 & 0.000 & 0.000 & & 0.004 \\
\hline $\mathrm{YCH}$ & -0.750 & 1.000 & 1.000 & 0.000 & 0.000 & -0.619 & 0.000 & -1.000 & -1.000 & 0.000 & -1.000 & -1.000 & 0.000 & 0.000 & 0.000 & 0.000 & 0.000 & 0.000 & 0.000 & 0.000 & 0.000 & 1.000 & 0.000 & 0.000 & 0.000 & 0.000 & \\
\hline
\end{tabular}

${ }^{*} p<0.05$

ITS locus (Table 2). That may be an evolutionary result of ITS between B. fatalis and B. longirostris.

\section{Genetic differentiation of $B$. fatalis and $B$. longirostris}

"Three Gradient Terrains" is a general description of Chinese terrain characters on relief amplitude. It portrays an outline of terrain changes like ladders along West-East direction. The first gradient terrain has the highest topography, with an altitude of over 2,600 m, mainly on the QTP. The second step is between $660 \mathrm{~m}$ and 2,600 $\mathrm{m}$ above sea level, with many large plateaus and basins. The third stair is below $660 \mathrm{~m}$ above sea level. In this study, B. fatalis was on the third stair (Table 1), where hills, low mountains and plains are interlaced [49]. The lower and similar altitude of waterbodies is good for gene communication between different population of zooplankton [9]. That may be the reason for the lower differentiation within $B$. fatalis than B. longirostris (Tables 3 and 4). On the other hand, it has reported that the geological isolation induced by different altitude can limit gene flow between subpopulation of zooplankton and lead to their differentiation [50]. $B$. longirostris was distributed on both the first and second steps (Table 1). The topographic drop between these

Table 4 Genetic distance (p-distance: upper diagonal) and the fixation index considering genetic distances (Fst: lower diagonal) among 13 geographical populations of B. longirostris in China

\begin{tabular}{llllllllllllll}
\hline & DPH & LHR & LUH & LXXR & PYH & BSTH & HSH & KDLH & TIC & WLGH & ELSR & CSH & FXH \\
\hline DPH & & 0.003 & 0.002 & 0.006 & 0.017 & 0.034 & 0.002 & 0.012 & 0.034 & 0.039 & 0.017 & 0.017 & 0.002 \\
LHR & 0.415 & & 0.001 & 0.008 & 0.017 & 0.033 & 0.004 & 0.010 & 0.033 & 0.039 & 0.017 & 0.017 & 0.004 \\
LUH & 0.143 & -0.043 & & 0.007 & 0.017 & 0.034 & 0.003 & 0.011 & 0.034 & 0.039 & 0.017 & 0.017 & 0.003 \\
LJXR & 0.059 & $0.664^{*}$ & $0.451^{*}$ & & 0.015 & 0.034 & 0.005 & 0.014 & 0.034 & 0.039 & 0.015 & 0.015 & 0.005 \\
PYH & 0.464 & 1.000 & 0.571 & 0.536 & & 0.034 & 0.017 & 0.016 & 0.034 & 0.041 & 0.004 & 0.004 & 0.017 \\
BSTH & $0.493^{*}$ & $0.666^{*}$ & $0.549^{*}$ & $0.513^{*}$ & 0.524 & & 0.035 & 0.032 & 0.018 & 0.012 & 0.032 & 0.032 & 0.035 \\
HSH & -0.013 & 1.000 & 0.543 & -0.246 & 1.000 & $0.620^{*}$ & & 0.014 & 0.035 & 0.039 & 0.017 & 0.017 & 0.000 \\
KDLH & $0.328^{*}$ & 0.250 & $0.208^{*}$ & $0.453^{*}$ & 0.444 & $0.393^{*}$ & $0.545^{*}$ & & 0.032 & 0.041 & 0.018 & 0.018 & 0.014 \\
TIC & $0.493^{*}$ & $0.666^{*}$ & $0.549^{*}$ & $0.513^{*}$ & 0.524 & -0.167 & 0.620 & $0.393^{*}$ & & 0.012 & 0.032 & 0.032 & 0.035 \\
WLGH & $0.732^{*}$ & $1.000^{*}$ & $0.786^{*}$ & $0.768^{*}$ & 1.000 & 0.192 & $1.000^{*}$ & $0.696^{*}$ & 0.192 & & 0.037 & 0.037 & 0.039 \\
ELSR & $0.569^{*}$ & $1.000^{*}$ & 0.650 & 0.573 & 1.000 & $0.620^{*}$ & 1.000 & $0.545^{*}$ & 0.620 & 1.000 & & 0.000 & 0.017 \\
CSH & $0.569^{*}$ & 1.000 & $0.650^{*}$ & $0.573^{*}$ & 1.000 & $0.620^{*}$ & 1.000 & $0.545^{*}$ & 0.620 & $1.000^{*}$ & 0.000 & \\
FXH & -0.013 & 1.000 & 0.543 & -0.246 & 1.000 & $0.620^{*}$ & 0.000 & $0.545^{*}$ & 0.620 & $1.000^{*}$ & 1.000 & 1.000 & 0.017 \\
\hline
\end{tabular}




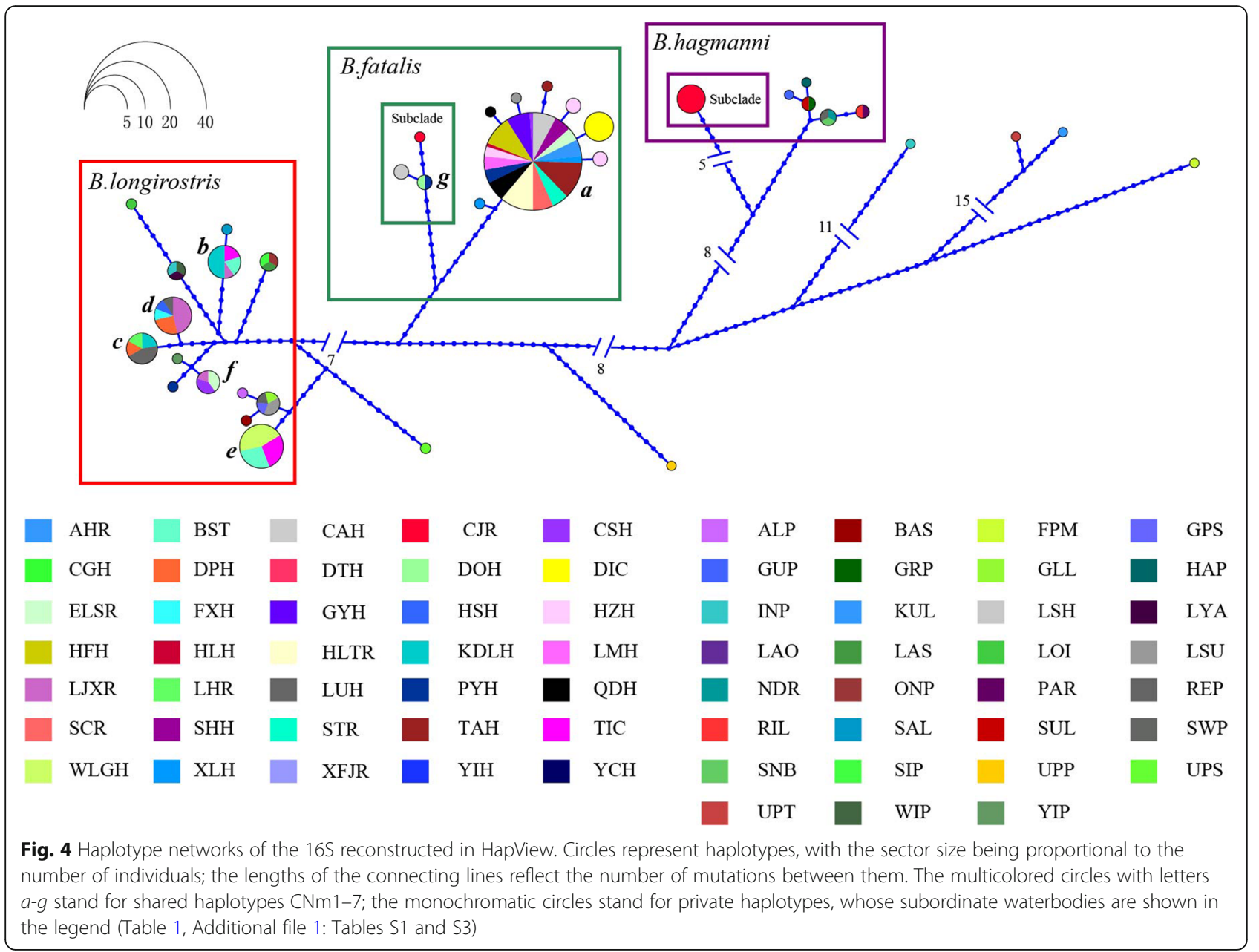

steps, about $1000 \mathrm{~m}$, reflects a strong gradient nature and may limit gene flow [49]. That may be responsible for the higher differentiation within $B$. longirostris (Tables 3 and 4). Due to differing mutation rates and increased rate of transitional saturation rate, $16 \mathrm{~S}$ will be more highly informative in biogeographic differentiation than ITS. Therefore, the higher differentiation may be shown in 16S, but not in ITS [19]. That should be explained for the different patterns of the haplotype networks obtained for B. longirostris at $16 \mathrm{~S}$ and ITS genes (Figs. 4 and 5).

\section{Different ecological preponderance of $B$. fatalis and $B$. longirostris}

A number of physical, chemical and biological factors in the habitat can influence the community structure of zooplankton, and the factors recognized as the most important by majority of investigators were temperature, the quality and availability of food, competition and predation [50-52]. Nevertheless, there were no marked differences between the growths of $B$. fatalis and $B$. longirostris in response to temperatures ranging from $10^{\circ}$ to $30{ }^{\circ} \mathrm{C}$ in a laboratory experiment [53]. Our temperature data of sampled waterbodies did not exceed this range $\left(13.4{ }^{\circ} \mathrm{C}\right.$ to $29.8^{\circ} \mathrm{C}$ ) (Table 1 ), which indicated that food, competition or predation seemed to more directly affect the population densities of $B$. fatalis and $B$. longirostris. The central and eastern waterbodies in our dataset (those on the NCR, YGP and the eastern of MXP and EPR) usually had very high trophic levels, while western waterbodies (those on the western of MXP and EPR) were mostly mesotrophic or oligotrophic and were less affected by human activities (Table 1). Eutrophication often causes an increased density of phytoplankton, especially the bloom of Microcystis [28]. In such condition, $B$. fatalis can overcome $B$. longirostris because of more efficient capture and utilization [54]. On the other hand, eutrophication favours cyclopoids, which can prey on Bosmina $[55,56]$. Previous study has shown that $B$. fatalis is a superior competitor against $B$. longirostris and is more resistant to predation [57]. Therefore, competitive edge induced by food and predation in eutrophic waterbodies can be responsible for the preponderance of $B$. fatalis in the central and eastern 


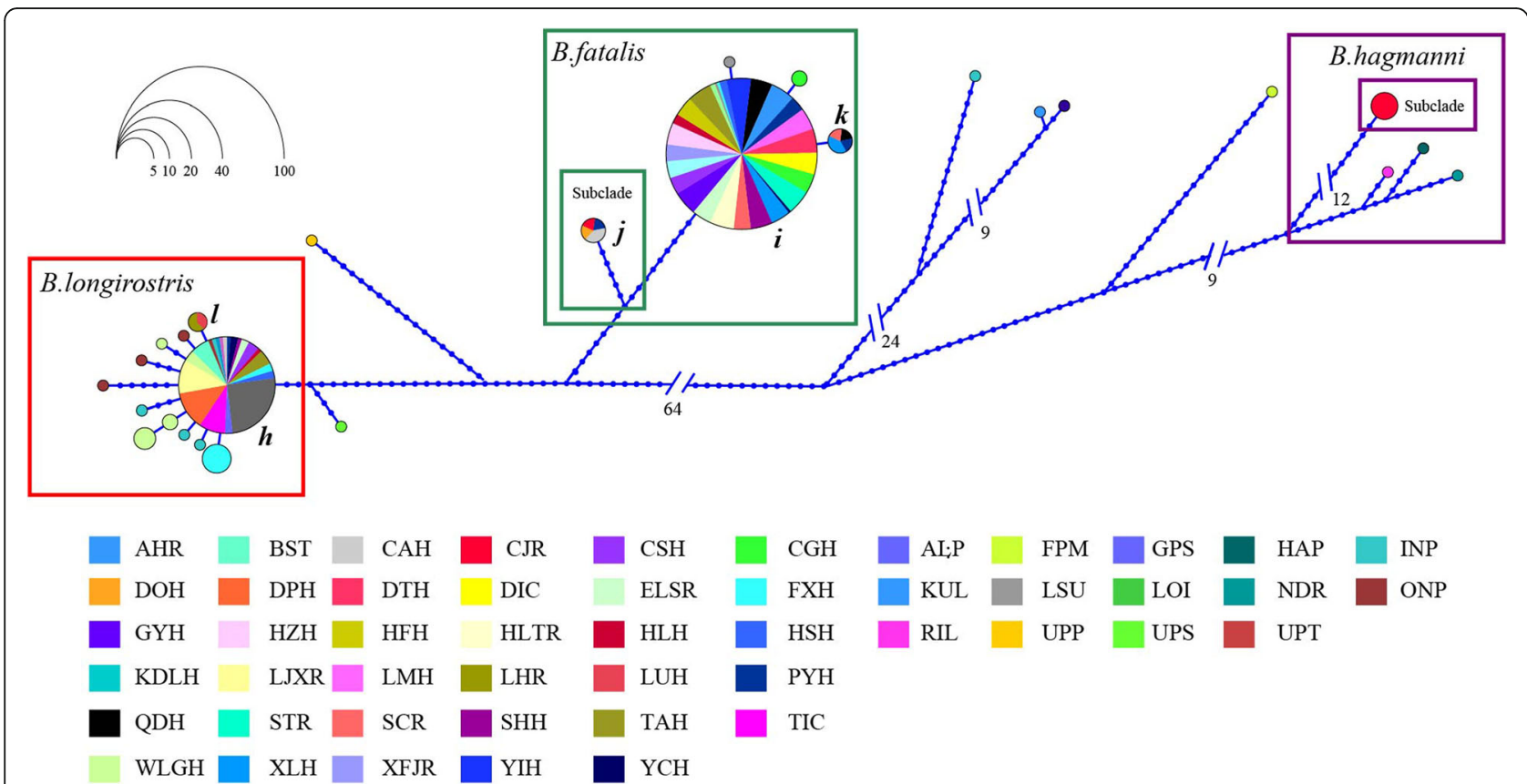

Fig. 5 Haplotype networks of the ITS reconstructed in HapView using an ML tree. Circles represent haplotypes, with the sector size being proportional to the number of individuals; the lengths of the connecting lines reflect the number of mutations between them. The multicolored circles with letters $\mathrm{h}$-/ stand for shared haplotypes CNn1 to CNn6; the monochromatic circles stand for private haplotypes, whose subordinate waterbodies are shown in the legend (Table 1, Additional file 1: Tables S1 and S3)

region. On the contrary, dominance of $B$. longirostris was observed in western waterbodies, which are mesotrophic/oligotrophic.

\section{Appearance of $B$. hagmanni in China}

We only found one lineage close to B. hagmanni in a single locality, the Changjiang Reservoir (CJR) in Guangdong province. B. hagmanni was thought to be confined to the American continent [58]. It seems that an American local lineage of $B$. hagmanni spread to the new continent, which is not surprising, since previous studies have shown that Bosmina can invade new continents by ship [59]. Guangdong province, which is in frequent maritime trade with America, may provide convenient conditions for alien Bosmina invasion [60]. Nevertheless, the invasion range in China should be quite limited (only present in one reservoir of our samples). A previous study suggested that the interaction between the trophic state and species identity influenced the invasion success of Cladocera [61, 62]. Although the waterbodies of Guangdong province are indeed eutrophic [63], we have little knowledge regarding the biological identity of $B$. hagmanni. Whether eutrophication also restricted the invasion range of $B$. hagmanni could be an interesting issue for future studies.

The limited distribution of Bosmina on the Tibetan plateau Although previous reports showed that Bosmina is a cosmopolitan genus of Cladocera, we did not find any species in 10 waterbodies of Tibetan Plateau, where the waterbodies have relatively limited phytoplankton for planktivorous zooplankton [28]. Due to the phenotypic plasticity of the filter screens, Daphnia adapted to the low-food environment [64] and may generate the effective monopoly of food resources, thereby avoiding the spread of other zooplankton [46]. The limited distribution of Bosmina on the Tibetan Plateau may be relative to the extensive distribution of Daphnia in the same region [11]. Moreover, the Tibetan Plateau, as the roof of the world (an elevation of more than $4,000 \mathrm{~m}$, average above sea level) surrounded by high mountains, is ecologically isolated from other regions of China [65]. The more isolated the habitat is, the smaller the probability is that species will colonize it, especially such species as zooplankton that disperse by passive means [66], which may be another reason why Bosmina spread into the Tibetan Plateau finitely.

\section{Conclusion}

Based on two genetic markers (mtDNA $16 \mathrm{~S}$ and a nuclear ITS), we identified individuals from the Bosmina that were sampled from 35 Chinese waterbodies as descendants of two primary species (B. fatalis and B. longirostris) with different spatial pattern, which may be related to their different evolutionary status (relict and non-relict). Their different genetic polymorphism also seems to an inertia of their own evolutionary status. Nevertheless, their different genetic differentiation may 
be related to the altitude of their habitat. Furthermore, $B$. fatalis was preponderant in central and eastern China, whereas $B$. longirostris was dominant in western China. Their different ecological dominance may result from competitive interaction induced by food and predation in different trophic waterbodies. Among the waterbodies sampled, the lineage close to alien $B$. hagmanni was found only at a single locality (CJR), which might be invaded. The limited distribution of Bosmina on the Tibetan Plateau is a feature, which could be explained by resource monopoly of Daphnia in isolated habitat.

\section{Additional files}

Additional file 1: Table S1. Numbers of observed haplotypes (of the 165 and ITS) in the investigated Chinese waterbodies; Table S2. The waterbodies where Bosmina was not found; Table S3. List of GenBank reference clones from Japanese, North American, European, Southern and Central Asian specimens used in phylogenetic analyses and haplotype networks. (DOCX $27 \mathrm{~kb})$

Additional file 2: The obtained haplotypes of 165 and ITS in this study. (DOCX $16 \mathrm{~kb}$ )

\section{Abbreviations}

16S: Partial 16S rDNA; AHR: Ahang Reservoir; BSTH: Bositeng Lake; CAH: Chao Lake; CGH: Chagan Lake; Chl. a: Chlorophyll-a; CJR: Changjiang Reservoir; CSH: Changshou Lake; DIC: Dianchi; DOH: Dong Lake; DPH: Dongping Lake; DTH: Dongting Lake; ELSR: Erlongshan Reservoir; EPR: Eastern Plain Region; FXH: Fuxian Lake; GYH: Gaoyou Lake; HFH: Hongfeng Lake; HLH: Hulun Lake; HLTR: Heilongtan Reservoir; HSH: Hasuhai Lake; HZH: Hongze Lake; ITS: Internal transcribed spacer; KDLH: Kundulun Lake; LHR: Luhun Reservoir LJXR: Liujiaxia Reservoir; LMH: Luoma Lake; LUH: Luo Lake; MXP: MongoliaXinjiang Plateau; NCR: Northeast China Region; PYH: Poyang Lake; QDH: Qiandao Lake; QTR: Tibetan Plateau; SCR: Sancha Reservoir; SD: Secchi disk visibility; SHH: Songhua Lake; STR: Songtao Reservoir; T.S.I.: Trophic state index; TAH: Tai Lake; TIC: TianChi; TP: Total phosphorus; WLGH: Wulungu Lake; WT: Water temperature; XFJR: Xinfengjiang Reservoir; XLH: Xiliang Lak; YCH: Yecheng Lake; YGP: Yunnan-Guizhou Plateau; YIH: Ying Lake

\section{Acknowledgements}

We thank Dr. Wei Hu and MingboYin for critical discussions and Dr. Xiaolin Ma for consulting on the data analysis. Meanwhile, we thank Feifei Liu, Lina Shao and Wen Gao who helped us with the sampling.

\section{Authors' contributions}

WW designed the study. YZ, LW and HZ carried out the analyses. LW wrote the manuscript. All authors read and approved the final manuscript.

\section{Funding}

This research was funded by grants from the Aquaculture Sanxin Project of Jiangsu Province (Y2016-19). This funding source had no role in the design of the study and collection, analysis, and interpretation of data and in writing the manuscript.

\section{Availability of data and materials}

The datasets supporting the conclusions of this article are included in this article and its additional files. In particular, Additional file 2 (the sequence data used in this study) is submitting to the GenBank databases under accession numbers: MH918683-MH918699 for 16S and MH918700-MH918711 for ITS.

\section{Ethics approval and consent to participate}

Not applicable.

\section{Consent for publication}

Not applicable.

\section{Competing interests}

The authors declare that they have no competing interests.

Received: 10 February 2019 Accepted: 8 July 2019

Published online: 16 July 2019

\section{References}

1. Sen LC, Fei WY, Gao SQ. Climate analysis of endemic species-a novel method for quantitative analysis of global climate change since tertiary. Acta Bot Sin. 2001;43:217-20 (in Chinese).

2. Korovchinsky NM. The Cladocera (Crustacea: Branchiopoda) as a relict group. Zool J Linnean Soc. 2006;147:109-24.

3. Willis KJ, Whittaker RJ. The refugial debate. Science. 2000;287:1406-7.

4. Ding L, Gan XN, He SP, et al. A phylogeographic, demographic and historical analysis of the short-tailed pit viper (Gloydius brevicaudus): evidence for early divergence and late expansion during the Pleistocene. Mol Ecol. 2011;20:1905-22.

5. Zhang HH, Dou HL, Chen L, et al. Genetic diversity and phylogenetic analysis of wolves from different geographical regions of China. Acta Ecol Sin. 2015:35:1869-81 (in Chinese).

6. Dufresnes C, Litvinchuk SN, Borzee A, et al. Phylogeography reveals an ancient cryptic radiation in east-Asian tree frogs (Hylajaponica group) and complex relationships between continental and island lineages. BMC Evol Biol. 2016;16:253.

7. Yang QW, Huang J. Research progress on genetic diversity of Oryza rufipogon in China. Acta Agron Sin. 2013:39:580-8 (in Chinese).

8. Zhang $\mathrm{YH}$, Wang IJ, Comes HP, et al. Contributions of historical and contemporary geographic and environmental factors to phylogeographic structure in a tertiary relict species, Emmenopterys henryi (Rubiaceae). Sci Rep. 2016;6:24041.

9. Ma X, Petrusek A, Wolinska J, et al. Diversity of the Daphnia longispina species complex in Chinese lakes: a DNA taxonomy approach. J Plankton Res. 2015;37:56-65.

10. Taylor DJ, Finston TL, Hebrt PDN. Biogeography of a widespread freshwater crustacean: pseudocongruence and cryptic endemism in the north american Daphnia laevis complex. Evolution. 1998:52:1648-70.

11. Xu L, Lin Q, Xu S, et al. Daphnia diversity on the Tibetan plateau measured by DNA taxonomy. Ecol Evol. 2018;8:5069-78.

12. Xu S, Hebert PDN, Kotov AA, et al. The noncosmopolitanism paradigm of freshwater zooplankton: insights from the global phylogeography of the predatory cladoceran Polyphemus pediculus (Linnaeus, 1761) (Crustacea, Onychopoda). Mol Ecol. 2009;18:5161-79.

13. Adamowicz SJ, Hebert PDN, Marinone MC. Species diversity and endemism in the Daphnia of Argentina: a genetic investigation. Zool J Linn Soci. 2004; 140:171-205.

14. Goulden CE, Frey DG. The occurrence and significance of lateral head pores in the genus Bosmina (Cladocera). Int Rev Hydrobiol. 1963;48:513-22.

15. Havens $K$, Decosta J. The effect of acidification in enclosures on the biomass and population size structure of Bosmina longirostris. Hydrobiologia. 1985; 122:153-8.

16. Huibin LU, Chen G, Chen X, et al. The long-term effects of bottom-up and topdown forcing on zooplankton: an example from sedimentary Bosminid records of lake dianchi and lake fuxian. J Lake Sci. 2015;27:67-75 (in Chinese).

17. Yun $L$, Ping $X$, Zhao $D$, et al. Eutrophication strengthens the response of zooplankton to temperature changes in a high-altitude lake. Ecol Evol. 2016; 6:6690-701

18. Kerfoot WC. Long-term replacement cycles in cladoceran communities: a history of predation. Ecology. 1981;62:216-33.

19. Taylor DJ, Ishikane CR, Haney RA. The systematics of Holarctic bosminids and a revision that reconciles molecular and morphological evolution. Limnol Oceanogr. 2002:47:1486-95.

20. Chiang SC, Du NS. Fauna sinica; crustacea: freshwater cladocera. Peking: Science Press; 1979. (in Chinese)

21. Lieder U. Introgression as a factor in the evolution of polytypical plankton Cladocera. Int Rev Hydrobiol. 1983;68:269-84.

22. Sakamoto M, Hanazato T. Proximate factors controlling the morphologic plasticity of Bosmina: linking artificial laboratory treatments and natural conditions. Hydrobiologia. 2009:617:171-9.

23. Kotov AA, Ishida S, Taylor DJ. Revision of the genus Bosmina Baird, 1845 (Cladocera: Bosminidae), based on evidence from male morphologica characters and molecular phylogenies. Zool J Linnean Soc. 2009;156:1-51. 
24. Costa FO, Dewaard JR, Boutillier J, et al. Biological identifications through DNA barcodes: the case of the Crustacea. Can J Fish Aquat Sci. 2007;64:272-95.

25. Faustova M, Sacherova V, Svensson J-E, et al. Radiation of European Eubosmina (Cladocera) from Bosmina(E.) longispina-concordance of multipopulation molecular data with paleolimnology. Limnol Oceanogr. 2011;56:440-50.

26. Haney RA, Taylor DJ. Testing paleolimnological predictions with molecular data: the origins of Holarctic Eubosmina. J Evol Biol. 2003;16:871-82.

27. Adamczuk M, Mieczan T, Tarkowska-Kukuryk M, et al. Rotatoria-CladoceraCopepoda relations in the long-term monitoring of water quality in lakes with trophic variation (E. Poland). Environ Earth Sci. 2015;73:8189-96.

28. Wang SM, Dou HS. Record of China Lakes. Beijing: Science Press; 1995. (in (hinese)

29. Huang XF. Survey, observation and analysis of lake ecology. Beijing: Standards Press of China; 1999. (in Chinese)

30. Carlson RE. A trophic state index for lakes. Limnol Oceanogr. 1977:22:361-80.

31. Schwenk K, Sand A, Boersma M, et al. Genetic markers, genealogies and biogeographic patterns in the Cladocera. Aquat Ecol. 1998;32:37-51.

32. Thompson JD, Higgins DG, Gibson TJ. CLUSTALW: improving the sensitivity of progressive multiple sequence alignment through sequence weighting, position-specific gap penalties and weight matrix choice. Nucleic Acids Res. 1994;22:4673-80.

33. Kumar S, Stecher G, Tamura K. Mega7: molecular evolutionary genetics analysis version 7.0 for bigger datasets. Mol Biol Evol. 2016; 33:1870-4.

34. Darriba D, Taboada GL, Doallo R, et al. jModeltest 2: more models, new heuristics and parallel computing. Nat Methods. 2012;9:772.

35. Stamatakis A, Hoover $P$, Rougemont J. A rapid bootstrap algorithm for the RAxML web servers. Syst Biol. 2008;57:758-71.

36. Librado P, Rozas J. DnaSP v5: a software for comprehensive analysis of DNA polymorphism data. Bioinformatics. 2009;25:1451-2.

37. Excoffier L, Laval G, Schneider S. Arlequin (version 3.0): An integrated software package for population genetics data analysis. Evol Bioinform. 2005;1:47-50.

38. Salzburger W, Ewing GB, Haeseler AV. The performance of phylogenetic algorithms in estimating haplotype genealogies with migration. Mol Ecol. 2011;20:1952-63.

39. Lieder U. Revision of the genus Bosmina Baird, 1845 (Crustacea, Cladocera) Int Rev Hydrobiol. 1983:68:121-39.

40. Krehenwinkel H, Graze M, Rodder D, et al. A phylogeographical survey of a highly dispersive spider reveals eastern Asia as a major glacial refugium for Palaearctic fauna. J Biogeogr. 2016;43:1583-94.

41. Ishida S, Kotov AA, Taylor DJ. A new divergent lineage of Daphnia (Cladocera: Anomopoda) and its morphological and genetical differentiation from Daphnia curvirostris Eylmann. Zool J Linnean Soc. 2006: 146:385-405.

42. Adamczuk M. Past, present, and future roles of small cladoceran Bosmina longirostris (O. F. müller, 1785) in aquatic ecosystems. Hydrobiologia. 2016;767:1-11.

43. Nevalainen L, Luoto TP, Kultti S, et al. Spatio-temporal distribution of sedimentary Cladocera (Crustacea: Branchiopoda) in relation to climate. J Biogeogr. 2013;40:1548-59.

44. Chang C-S, Kim H, Park TY, et al. Low levels of genetic variation among southern peripheral poulations of the threatened herb, Leontice microrhyncha (Berberidaceae) in Korea. Biol Conserv. 2004;119:387-96.

45. Hampe A, Jump AS. Climate relicts: past, present, future. Annu Rev Ecol Evol Syst. 2011:42:313-33

46. De Meester L, Gomez A, Okamura B, et al. The monopolization hypothesis and the dispersal-gene flow paradox in aquatic organisms. Acta Oecol. 2002;23:121-35.

47. Navajas M, Lagnel J, Gutierrez J. Species wide homogeneity of nuclear ribosomal ITS2 sequences in the spider mite Tetranychus urticae contrasts with extensive mitochondrial COI polymorphism. Heredity. 1998:80:742-52.

48. Campbell BC, Steffen-Campbell JD, Werren HJ. Phylogeny of the Nasonia species complex (Hymenoptera: Pteromalidae) inferred from an internal transcribed spacer (ITS2) and $28 \mathrm{~S}$ rDNA sequences. Insect Mol Biol. 1993:2:225-37.

49. Jie J, Xin Y. Quantitative segmentation of the three gradient terrain of China based on DEM. Geomatics World. 2009;1:8-13 (in Chinese)
50. Sampaio EV, Rocha O, Matsumura-Tundisi T et al. composition and abundance of zooplankton in the limnetic zone of seven reservoirs of the Paranapanema River, Brazil. Braz J Biol. 2002;62:525-45.

51. Johannsson OE, Robert OG. Roles of predation, food, and temperature in structuring the epilimnetic zooplankton populations in Lake Ontario, 1981-1986. T Am Fish Soc. 1991;120:193-208.

52. Nowicki CJ, Bunnell DB, Armenio PM, et al. Biotic and abiotic factors influencing zooplankton vertical distribution in lake huron. J Great Lakes Res. 2017. https://doi.org/10.1016/j.jglr.2017.08.004.

53. Hanazato T, Masayuki Y. Effect of temperature in the laboratory studies on growth, egg development and first parturition of five species of Cladocera. Jpn J Limnol. 1985;46:185-91.

54. Hanazato T, Yasuno M. Experimental studies on competition between Bosmina longirostris and Bosmina fatalis. Hydrobiologia. 1987;154:189-99.

55. Maier G. Differential success of cyclopoid copepods in the pelagic zone of eutrophic lakes. J Marine Sys. 1998;15:135-8.

56. Kerfoot WC. Combat between predatory copepods and their prey: Cyclops, Epischura, and Bosmina. Limnol Oceanogr. 1978;23:1089-102.

57. Chang $\mathrm{KH}$, Hanazato T. Predation impact of Leptodora kindtii on population dynamics and morphology of Bosmina fatalis and B. longirostris in mesocosms. Freshw Biol. 2004;49:253-64.

58. Beaver JR, Renicker TR, Tausz CE, et al. Distribution of six taxa in the family Bosminidae Baird (Crustacea: Branchiopoda: Anomopoda) in the plankton of lakes and reservoirs within the continental United States, including expanded range of the invasive cladoceran Bosmina (Eubosmina) coregoni Baird. Zootaxa. 2018:4407:506-20.

59. Santagata $S$, Gasiūnaite ZR, Verling $E$, et al. Effect of osmotic shock as a management strategy to reduce transfers of non-indigenous species among low-salinity ports by ships. Aquat Invasions. 2008;3:61-71.

60. Huang QC. Two thousand years of Guangdong's opening foreign trade___around Guangzhou. Shenzhen Univ J. 2007;24:150-7 (in Chinese).

61. Lennon JT, Smith VH, Dzialowski AR. Invasibility of plankton food webs along a trophic state gradient. Oikos. 2003:103:191-203.

62. Mello N, Maia-Barbosa PM. Cyanobacteria bloom: selective filter for zooplankton? Braz J Biol. 2015;75:165-74.

63. Jiang T, Liu Z, Chen X, et al. Assessment of reservoir eutrophication in Guangdong province. J Lake Sci. 2005;17:378-82 (in Chinese).

64. Lampert W. Phenotypic plasticity of the filter screens in Daphnia: adaptation to a low-food environment. Limnol Oceanogr. 1994:39:997-1006.

65. Wu T. The Qinghai-Tibetan plateau: how high do Tibetans live? High Alt Med Biol. 2001;2:489-99.

66. MacArthur Rl, Wilson EO. The theory of island biogeography. New Jersey: Princeton Univ Press; 1967

\section{Publisher's note}

Springer Nature remains neutral with regard to jurisdictional claims in published maps and institutional affiliations.

Ready to submit your research? Choose BMC and benefit from:

- fast, convenient online submission

- thorough peer review by experienced researchers in your field

- rapid publication on acceptance

- support for research data, including large and complex data types

- gold Open Access which fosters wider collaboration and increased citations

- maximum visibility for your research: over $100 \mathrm{M}$ website views per year

At BMC, research is always in progress.

Learn more biomedcentral.com/submissions 